\title{
Haploporus mugilis sp. n. (Digenea: Haploporidae) from Valamugil engeli (Pisces: Mugilidae) in the Taiwan Straits, China
}

\author{
Liu Sheng-fa ${ }^{1,2}$ and Yang Ting-bao ${ }^{2}$ \\ ${ }^{1}$ Parasitology Research Laboratory, School of Life Sciences, Xiamen University, Xiamen, 361005, China; \\ ${ }^{2}$ State Key Laboratory for Biocontrol \& School of Life Sciences, Zhongshan University, Guangzhou, 510275, China
}

Key words: Digenea, Haploporus, Valamugil engeli, Taiwan Straits

\begin{abstract}
Haploporus mugilis sp. n. (Digenea: Haploporidae) was obtained from the intestine of kandas, Valamugil engeli (Bleeker) (Mugilidae, Perciformes) in the Taiwan Straits, China. It most closely resembles Haploporus spinosus Machida, 1996 from the intestine of Crenimugil crenilabis in Japanese and adjacent waters in the intestinal bifurcation posterior to the acetabulum, in egg-size $(0.039-0.044 \times 0.019-0.022$ in H. mugilis and 0.034-0.042 $\times 0.018-0.023$ in H. spinosus $)$ and in the hermaphroditic sac armed with spines. However, it differs from the latter in its hermaphroditic sac with two long and numerous small spines rather than with four long and six small spines and in the excretory vesicle with a single prominent refractory concretion instead of being empty.
\end{abstract}

Mugilid fishes (kandas) are widely distributed in the coastal waters, brackish waters and estuaries of tropical and subtropical zones and can serve as the second intermediate and the final hosts of many digenetic trematodes. Because they can live in different water environments, their importance as an agency in carrying the haploporid trematodes to different parts of the world is very significant. During a study of the helminths of marine fishes from the Taiwan Straits, China, a new species of Haploporus Looss, 1902 was recovered from the intestines of kandas.

\section{MATERIALS AND METHODS}

Freshly caught kandas, Valamugil engeli (Bleeker) were collected from the coast of Xiamen $\left(24^{\circ} 25^{\prime} 24^{\prime \prime}-33^{\prime} 14^{\prime \prime} \mathrm{N}\right.$, 118 03'58'-11'48’E), Fujian Province, People's Republic of China, and then kept alive in aquaria until examined. All helminths were recovered alive, and fixed under a cover glass in $10 \%$ formalin solution, stained in Grenacher's alcoholborax carmine, dehydrated, cleared in clove oil, and mounted in Canada balsam. The figures were drawn with the aid of a drawing apparatus. Measurements are given in millimetres, as the ranges followed by the mean in parentheses, unless otherwise stated. "Sucker ratio" refers to the ratio of the sum of the length and width of the oral sucker to that of the acetabulum.

\section{RESULTS}

\section{Haploporus mugilis sp. $\mathrm{n}$.}

Figs. 1-4

Description: Measurements based on 12 specimens. Body spindle-shaped, 1.32-2.32 (1.81) long by 0.29$0.52(0.42)$ wide, with spines extending full length of body, but decreasing in density posteriorly. Oral sucker almost rounded, terminal, 0.066-0.104 (0.082) long by
0.108-0.170 (0.142) wide. Acetabulum 0.088-0.134 (0.112) long by $0.108-0.136(0.117)$ wide, at posterior part of anterior third of body. Sucker ratio $1: 0.88-1$ : 1.21 (1 : 1.03). Prepharynx 0.010-0.046 (0.024) long; pharynx pyriform, $0.062-0.090$ (0.077) long by 0.040 0.090 (0.060) wide; oesophagus 0.320-0.744 (0.515) long, bifurcating immediately posterior or a little distance posterior to acetabulum. Caeca cylindrical, terminating blindly anterior to or at level of ovary.

Testis single, elliptical, 0.288-0.536 (0.359) long by $0.100-0.188(0.135)$ wide, at middle or anterior half of hindbody. Two vasa efferentia arising from anterodorsal margin of testis and turning forward without forming vas deferens. Post-testicular space 0.224-0.520 (0.409) long. External seminal vesicle subcylindrical, 0.096-0.204 (0.128) long by $0.050-0.076(0.062)$ wide Hermaphroditic sac $0.224-0.336(0.287)$ long by $0.144-$ $0.272(0.183)$ wide, dorsal to acetabulum, containing tubular internal seminal vesicle, $0.124-0.270(0.179)$ long by $0.050-0.086(0.061)$ wide, pars prostatica short, prostatic cells well developed, muscular metraterm 0.086-0.140 (0.112) long by 0.044-0.088 (0.062) wide, and hermaphroditic duct $0.138-0.180(0.158)$ long by 0.080-0.110 (0.096) wide, armed with two large spines, $0.022-0.033$ (0.027) long by 0.007-0.012 (0.009) wide, at its base and numerous small spines (Figs. 3-4). Genital pore immediately in front of acetabulum, with a circle of about 25 spine-like structures (Fig. 3).

Ovary spherical, $0.078-0.116(0.103)$ long by 0.080 $0.120(0.105)$ wide, median, anterior to or partially overlapping anterior border of testis. True seminal receptacle not present. Proximal portion of uterus filled with sperm. Laurer's canal 0.366-0.410 (0.389) long, extending a short distance posterior to testis. Vitellaria represented by two symmetrical compact masses, 


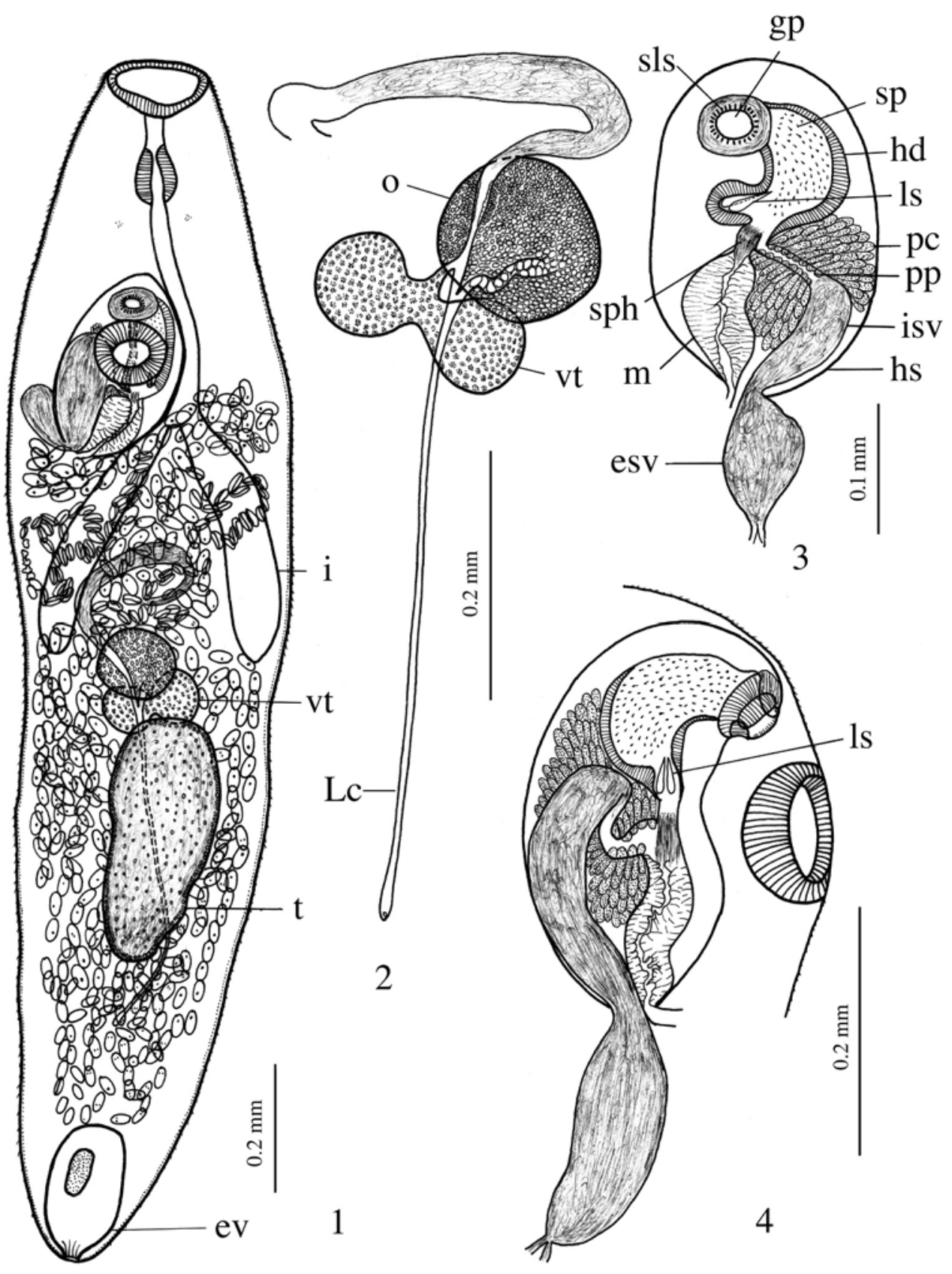

Figs. 1-4. Haploporus mugilis sp. n. Fig. 1. Holotype, ventral view. Fig. 2. Ovarian complex. Fig. 3. Ventral view of terminal genitalia. Fig. 4. Lateral view of terminal genitalia. Abbreviations: esv - external seminal vesicle; ev - excretory vesicle; gp - genital pore; hd - hermaphroditic duct; hs - hermaphroditic sac; i - intestine; isv - internal seminal vesicle; Lc - Laurer's canal; ls - large spine; $\mathrm{m}$ - metraterm; o - ovary; pc - prostatic cell; pp - pars prostatica; sls - spine-like structure; sp - small spine; sph - sphincter; $\mathrm{t}$ - testis; $\mathrm{vt}$ - vitellarium.

dumbbell-shaped, between the ovary and testis, sometimes slightly overlapping posterior border of the ovary or anterior border of the testis, each compact mass 0.060-0.104 (0.080) long by 0.052-0.076 (0.064) wide. Uterus reaching near posterior end of body. Eggs in the distal portion of the uterus $0.039-0.044(0.043)$ long by 0.019-0.022 (0.021) wide, elliptical, thin-walled, with well-developed miracidium with two pigment eyespots.
In some specimens these two pigment eyespots were so close to one another that they seemed to be a single large eyespot. Excretory vesicle saccular, with a prominent refractory concretion. Excretory pore terminal.

$\mathrm{T}$ y $\mathrm{p}$ e $\mathrm{h}$ o s t : Valamugil engeli (Bleeker) (Mugilidae, Perciformes).

Site of infection: Intestine.

Type loc ality: Xiamen, Fujian Province, China. 
Prevalence and intensity: $72 \%$ (31 fish infected/ 43 examined), 1-158 (22) helminths per fish.

$\mathrm{S} p$ e c i m e n s d e p o s i t e d : Holotype No. fjxm20010210-1 and paratypes Nos. fjxm20010210-2-3, fjxm20010208-1-5 and fjxm20010211-1-4 are deposited in Parasitology Research Laboratory, Xiamen University, People's Republic of China. Two paratypes, BM(NH) 2001.8.6.1-2, are deposited in The Natural History Museum, London. Two paratypes, USNPC No. 91707, are deposited in the U.S. National Parasite Collection in Beltsville, Maryland, and three paratypes, No. D-456, are deposited in the helminthological collection of the Institute of Parasitology, Academy of Sciences of the Czech Republic, České Budějovice.

E t y m o 1 o g y: The species name refers to the family Mugilidae of the type host, Valamugil engeli.

\section{DISCUSSION}

According to Yamaguti (1971), the subfamily Haploporinae contains six genera, viz., Haploporus Looss, 1902; Lecithobotrys Looss, 1902; Megacoelium Szidat, 1954; Neohaploporus Manter, 1963; Saccocoelioides Szidat, 1954; and Saccocoelium Looss, 1902. The genus Haploporus was erected by Looss (1902) with Distomum benedeni (Stossich, 1887) from the intestine of Mugil chelo and M. cephalus from the Gulf of Naples and Haploporus lateralis from M. auratus and M. labrosus from Trieste. It differs from Lecithobotrys, Megacoelium, Neohaploporus and Saccocoelioides in its vitellaria divided into two symmetrical compact masses instead of into follicles or lobed masses, or bunch-like. It is most similar to the genus Saccocoelium in possessing two symmetrical compact masses vitellaria, but can be distinguished from the latter in possessing cylindrical caeca rather than saccular caeca.

Seven species of Haploporus Looss, 1902 have been described to date, viz., H. benedeni (Stossich, 1887); $H$. lateralis Looss, 1902; H. longicollum (Wlassenko, 1931); H. indicus Rekharani et Madhavi, 1985; $H$. pseudoindicus Rekharani et Madhavi, 1985; H. spinosus Machida, 1996; and H. magnisaccus Machida, 1996. All of them are from the mugilid fishes, and only one of them, H. spinosus, has the hermaphroditic duct armed with spines. These species divide into two groups, based on the location of the intestinal bifurcation. In the typespecies, $H$. benedeni, and in $H$. lateralis and $H$. indicus, the intestinal bifurcation is anterior to or at the level of the acetabulum. On the other hand, in H. longicollum, $H$. pseudoindicus, $H$. spinosus and $H$. magnisaccus, the intestinal bifurcation is posterior to the acetabulum.

Haploporus mugilis most closely resembles $H$. spinosus from Crenimugil crenilabis in Japanese and adjacent waters in the intestinal bifurcation posterior to the acetabulum, in egg-size $(0.039-0.044 \times 0.019-0.022$ in H. mugilis and $0.034-0.042 \times 0.018-0.023$ in $H$. spinosus) and in the hermaphroditic sac armed with spines. However, it mainly differs from the latter in its hermaphroditic sac with two long and numerous small spines rather than with four long and six small spines and in excretory vesicle with a single prominent refractory concretion, a structure not described by Machida (1996) nor evident in his figure of $H$. spinosus.

Haploporus mugilis is similar to $H$. magnisaccus Machida, 1996 in the intestinal bifurcation posterior to the acetabulum and excretory vesicle with a single concretion, but differs from it in the hermaphroditic duct with two long and numerous small spines instead of with short, thick-walled diverticula.

Haploporus mugilis is similar to H. longicollum and $H$. pseudoindicus in the intestinal bifurcation posterior to the acetabulum, but can be distinguished from them by possessing the hermaphroditic duct with two long and numerous small spines rather than without spines.

Haploporus mugilis differs from $H$. benedeni, $H$. lateralis and $H$. indicus in the position of the intestinal bifurcation which is posterior to the acetabulum in $H$. mugilis but anterior to or at the level of the acetabulum in $H$. benedeni, $H$. lateralis and $H$. indicus and in the hermaphroditic duct with two long and numerous small spines in $H$. mugilis rather than without spines in $H$. benedeni, $H$. lateralis and $H$. indicus.

Acknowledgements. This study was supported by the National Natural Science Fund of China, grant No. 39870144, and the Natural Science Fund of Fujian Province, China, grant No. B0010002.

\section{REFERENCES}

LOOSS A. 1902: Die Distomen-Unterfamilie der Haploporinae. Arch. Parasitol. 6: 129-143.

MACHIDA M. 1996: Digenean trematodes from mullets in Japanese and adjacent waters. Jpn. J. Parasitol. 45: 123133.

Received 12 June 2001
YAMAGUTI S. 1971: Synopsis of Digenetic Trematodes of Vertebrates. Vols. 1-2. Keigaku. Publ. Co., Tokyo, 1,074 pp.

Accepted 10 September 2001 